\title{
EXPERIMENTAL INVESTIGATION INTO THE EFFECT OF AGGREGATE SIZE ON DYNAMIC COMPRESSIVE STRENGTH OF MORTAR AND CONCRETE
}

\author{
KYOUNG-MIN KIM, SANGHO LEE \& JAE-YEOL CHO \\ Concrete Structures Laboratory, Seoul National University, South Korea
}

\begin{abstract}
Split Hopkinson pressure bar (SHPB) has been widely used to the obtain dynamic strength of materials such as metals and concrete-like materials at high strain rates. A specimen size for SHPB test is limited depending on diameters of each SHPB apparatus. Especially for concrete SHPB test, maximum aggregate of small size has been used to avoid constraints in preparing small specimens. However, it has not been validated whether specimen with small maximum aggregate represents concrete material properties with large maximum aggregate size used normally for concrete structures, or not. This study conducted concrete and mortar SHPB tests under the same test conditions using a variety of maximum aggregate sizes to investigate the effect of maximum aggregate size on results of SHPB test. Then, the obtained values of dynamic increase factor (DIF), which is defined as a ratio of dynamic compressive strength to static compressive strength, were compared to one another. The results show that it is necessary to consider the effect of maximum aggregate size on concrete compressive DIF. In addition, the results can be used to establish guidance about the specimen of SHPB test.

Keywords: concrete, mortar, compressive strength, split Hokinson pressure bar, maximum aggregate size, dynamic increase factor.
\end{abstract}

\section{INTRODUCTION}

With increasing interest in extreme events like impacts, explosions among others there have been efforts to obtain precise dynamic material properties of concrete-like materials which are usually used in many structures. Split Hokinson pressure bar (SHPB) is one of apparatus to obtain the dynamic strength of materials such as metals and concrete-like materials at high strain rates. Since the specimen size for SHPB test is limited depending on diameters of SHPB apparatus, however, mortar or concrete with maximum aggregate of small size has been used to obtain dynamic strength which has low reliability because it is differ from the maximum aggregate size that has been used in practice.

Therefore, to find out whether the aggregate affects the dynamic strength of concrete-like materials or not, several researchers conducted numerical studies and experimental studies, which will be dealt with in the next section. Through the previous research, the effect of aggregate on dynamic strength has been found. However, there are no numerical or experimental studies that can reveal the effect of maximum aggregate size on dynamic strength of concrete-like materials. Moreover, the previous studies have not used aggregate of general size such as $25 \mathrm{~mm}$ but have used aggregate of small size such as $8 \mathrm{~mm}$ which cannot be considered as real behaviour of concrete-like material.

In this study, SHPB test with mortar and concrete specimens under the same test condition using a variety of maximum aggregate size was conducted to investigate the effect. And by comparing apparent dynamic increase factor (DIF) of compressive strength, which involves rate effect and other effects such as inertia effect and etc., the effect of homogeneity according to the maximum aggregate size was investigated. Furthermore, to consider pure rate effect on mortar and concrete, pure rate DIF suggested by Lee et al. [1] was calculated and compared according to the maximum aggregate size. 


\section{LITERATURE REVIEW}

To investigate the effect induced by aggregate, several previous researchers have conducted numerical and experimental studies. The previous studies, which will be mentioned below, have confirmed that the presence of aggregate or proportion of aggregate affects the dynamic strength of concrete. However, the studies were insufficient to reveal the effect of maximum aggregate size.

\subsection{Numerical studies}

Hao et al. [2] proposed two kinds of numerical model: homogeneous model and mesoscale model to simulate SHPB test for the purpose of investigating the effect of aggregate on DIF of compressive strength, which is expressed as a ratio of dynamic compressive strength to static compressive strength such as eqn (1) below. In eqn (1), $f_{c, d}$ and $f_{c, s}$ denote dynamic strength and static strength, relatively,

$$
D I F=\frac{f_{c, d}}{f_{c, s}}
$$

First, the homogeneous model considers concrete as homogeneous material like mortar. And the mesoscale model is consisted of three parts: mortar paste, coarse aggregate (maximum aggregate size is assumed as $32 \mathrm{~mm}$ ) and interfacial transition zone (ITZ). For all model, the specimen diameter and length are set as $100 \times 100 \mathrm{~mm}$.

The result indicates that at higher strain rate, the mesoscale model, which involves the aggregate part, shows higher strength enhancement than the homogeneous model. This is supported by the fact that, at high strain rate, there is not enough time for cracks to develop through mortar paste, which has lower strength than coarse aggregate as shown in Fig. 7 of reference [2].

Through the result of numerical study, it was confirmed that the presence of aggregate can affect the DIF of compressive strength. However, experiment was not conducted to support the result.

Hao and Hao [3] conducted numerical study to figure out the influence of aggregate proportion on DIF of compressive strength of mortar and concrete. Four cases of different percentage of coarse aggregate $(0 \%, 20 \%, 30 \%$ and $40 \%)$ were used in this numerical study. The simplified SHPB test model proposed by Hao et al. [4] was used to model mortar specimen with aggregate content of $0 \%$ and concrete specimens with different aggregate contents of $20 \%, 30 \%$ and $40 \%$.

As shown in Fig. 23 of reference [3], the specimens containing the coarse aggregate show higher DIF than specimen consisted of mortar matrix only. This indicates that DIF shows difference depending on the percentage of aggregate.

However, in this research, only the numerical study was carried out to investigate the effect of aggregate proportions on DIF. To verify the influence of aggregate on DIF of compressive strength, research about the maximum aggregate size should be conducted.

\subsection{Experimental studies}

Chen et al. [5] conducted SHPB test with pulse shaping technique to identify dynamic material properties of concrete-like materials, i.e. cement paste, mortar and concrete with maximum aggregate size $9 \mathrm{~mm}$. 
The test results shown in Fig. 12 of reference [5] represent that the dynamic compressive strength of mortar is higher than other materials. For DIF of compressive strength, cement paste shows the highest strength enhancement of compressive strength, though.

According to the results, it was revealed that presence of fine aggregate (mortar) and coarse aggregate (concrete) affects the dynamic strength of the materials. However, this research didn't consider the effect of coarse aggregate maximum size.

Hao et al. [6] carried out SHPB test of mortar and concrete with different maximum aggregate size $(4 \mathrm{~mm}, 8 \mathrm{~mm})$. As shown in Fig. 7 of reference [6], concrete with small aggregate shows higher DIF than with large aggregate and mortar, respectively. Moreover, it is shown that the test results of the concrete specimen with aggregate of larger size is more dispersive as heterogeneity of specimen increases.

However, the maximum aggregate size that used in this experimental study, $4 \mathrm{~mm}$ and 8 $\mathrm{mm}$, is relatively small compared to the aggregate using in practice such as $25 \mathrm{~mm}$.

\subsection{Limitations of previous studies}

The numerical studies and experimental studies have been carried out to identify the effect of aggregate on DIF of compressive strength of concrete-like materials based on SHPB test. Through the studies, the influence induced by the presence of aggregate and percentage of aggregate was confirmed. Moreover, in the study of Hao et al. [6] the effect of maximum aggregate size was suggested. However, overall, experimental studies to figure out the effect of aggregate according to the maximum size is insufficient. In addition, the numerical studies and experimental studies conducted only with small size of aggregate compared to the general concrete with maximum aggregate size such as $25 \mathrm{~mm}$. Therefore, it is difficult to understand that those behaviour represents precise dynamic compressive strength of concrete used in practice.

In order to overcome limitations mentioned above, SHPB test of concrete to figure out the size effect of coarse aggregate is necessary. In this study, the SHPB test of mortar and concrete with different maximum aggregate size of $13 \mathrm{~mm}, 19 \mathrm{~mm}$, and $25 \mathrm{~mm}$ was conducted under the same test condition except for the maximum aggregate size. Then, the apparent DIFs, which involve other effects as well as rate effect, were calculated as the ratio of compressive strength to find out the influence of heterogeneity induced by the different size of aggregate. Furthermore, the pure rate DIFs, which removes the inertia effect from the apparent DIF, suggested by Lee et al. [1], were evaluated to confirm the effect of maximum aggregate size on strength enhancement at various strain rate.

\section{EXPERIMENTAL PROGRAM}

In order to overcome the limitations of previous research as mentioned above, static compressive strength test and SHPB test of mortar and concrete specimen was conducted in this study.

\subsection{Specimen preparation}

Since the purpose of this experiment is identification of the size effect of aggregate, only the maximum aggregate size is substituted for the same mix proportion specified Table 1.

Specimens were cured according to ASTM C192/C192M, and after curing 50 days, the 3cylinder specimens with diameter and length of $150 \times 300 \mathrm{~mm}$ were grinded for static compressive strength test. 
Table 1: Mix proportion of mortar and concrete.

\begin{tabular}{|c|c|c|c|c|c|c|c|}
\hline \multicolumn{2}{|c|}{} & \multicolumn{5}{|c|}{ Unit weight $\left(\mathrm{kg} / \mathrm{m}^{3}\right)$} \\
\hline & W/C (\%) & s/a (\%) & C & W & S & G & SP \\
\hline Mortar & 34.8 & - & 480 & 167 & 672 & - & 4.32 \\
\hline Concrete & 34.8 & 40.9 & 480 & 167 & 692 & 1019 & 4.32 \\
\hline
\end{tabular}

And 30-cylinder specimens with diameter and length of $75 \times 150 \mathrm{~mm}$ were cut into $75 \times 75$ $\mathrm{mm}$ for SHPB test per each group of aggregate size. The specimens for SHPB test are shown in Fig. 1.

\subsection{Static compressive strength test}

Static compressive strength test was conducted according to ASTM C192/192M. The result of static compressive strength test is represented in Table 2.

\subsection{SHPB test}

In order to satisfy dynamic equilibrium of specimen, the pulse shaping technique were used. The pulse shaper dimensions are obtained through FEA using LS-DYNA and it was made of C1020 copper.

In order to obtain test results at various strain rates, three of impact velocity were used.

The specified test conditions are shown in Table 3.

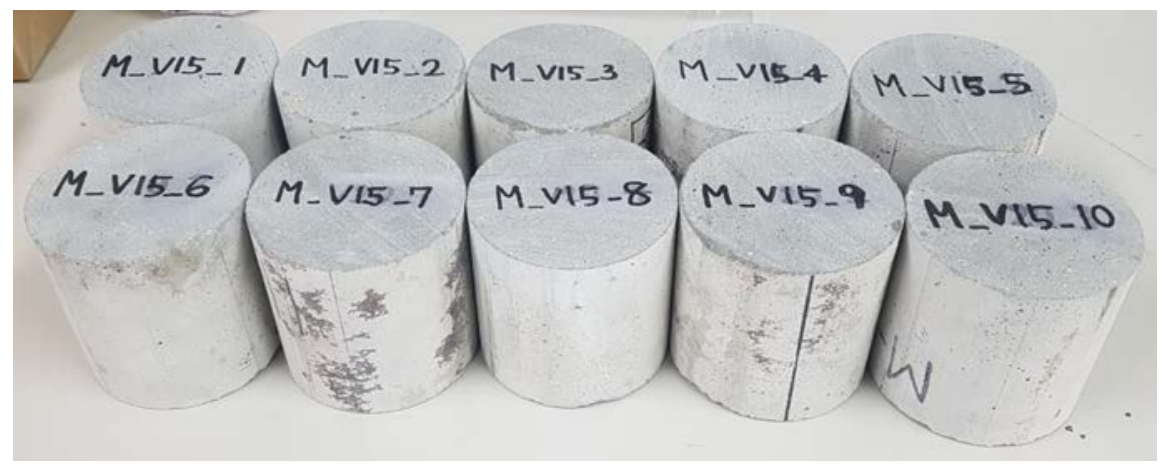

Figure 1: Mortar specimens for SHPB test.

Table 2: Static compressive strength test result.

\begin{tabular}{|c|c|c|}
\hline & $\begin{array}{c}\text { Static strength } \\
(\mathrm{MPa})\end{array}$ & $\begin{array}{c}\text { Density } \\
\left(\mathrm{kg} / \mathrm{m}^{3}\right)\end{array}$ \\
\hline Mortar & 67.2 & 2,235 \\
\hline $\mathrm{G}_{\max } 13 \mathrm{~mm}$ concrete & 66.7 & 2,433 \\
\hline $\mathrm{G}_{\max } 19 \mathrm{~mm}$ concrete & 68.5 & 2,401 \\
\hline $\mathrm{G}_{\max } 25 \mathrm{~mm}$ concrete & 64.0 & 2,514 \\
\hline
\end{tabular}


Table 3: SHPB test condition.

\begin{tabular}{|c|c|c|c|c|c|}
\hline $\begin{array}{c}\text { Specimen } \\
\text { dimension } \\
(\mathrm{mm})\end{array}$ & $\begin{array}{c}\mathrm{G}_{\max } \\
(\mathrm{mm})\end{array}$ & $\begin{array}{c}\text { Impact } \\
\text { velocity } \\
(\mathrm{m} / \mathrm{s})\end{array}$ & $\begin{array}{c}\text { Striker bar } \\
\text { length } \\
(\mathrm{mm})\end{array}$ & $\begin{array}{l}\text { Pulse shaper } \\
\text { dimension } \\
(\mathrm{mm})\end{array}$ & $\begin{array}{c}\text { The number } \\
\text { of specimens } \\
\text { (ea.) }\end{array}$ \\
\hline \multirow{12}{*}{$\Phi 75 \times 75$} & \multirow{3}{*}{ Mortar } & 10 & 600 & $52 \times 48 \times 3$ & 10 \\
\hline & & 15 & 300 & $52 \times 48 \times 3$ & 10 \\
\hline & & 20 & 300 & $51 \times 47 \times 3$ & 10 \\
\hline & \multirow{3}{*}{13} & 10 & 600 & $52 \times 48 \times 3$ & 10 \\
\hline & & 15 & 300 & $52 \times 48 \times 3$ & 10 \\
\hline & & 20 & 300 & $51 \times 47 \times 3$ & 10 \\
\hline & \multirow{3}{*}{19} & 10 & 600 & $52 \times 48 \times 3$ & 10 \\
\hline & & 15 & 300 & $52 \times 48 \times 3$ & 10 \\
\hline & & 20 & 300 & $51 \times 47 \times 3$ & 10 \\
\hline & \multirow{3}{*}{25} & 10 & 600 & $52 \times 48 \times 3$ & 10 \\
\hline & & 15 & 300 & $52 \times 48 \times 3$ & 10 \\
\hline & & 20 & 300 & $51 \times 47 \times 3$ & 10 \\
\hline
\end{tabular}

\section{TEST RESULTS}

\subsection{Apparent DIF}

In order to evaluate the influence of heterogeneity induced by the presence of aggregate and different maximum aggregate size, apparent DIF, which is expressed by eqn (1), and coefficient of variation (C.O.V.) of the apparent DIF were calculated.

As shown in Fig. 2, there is no significant tendency depending on the maximum aggregate size.

\subsection{Pure rate DIF}

In order to compare pure rate effect according to the maximum aggregate size, pure rate DIF, which is expressed as eqn (2), were calculated and compared. In eqn (2), $k_{1}$ was obtained

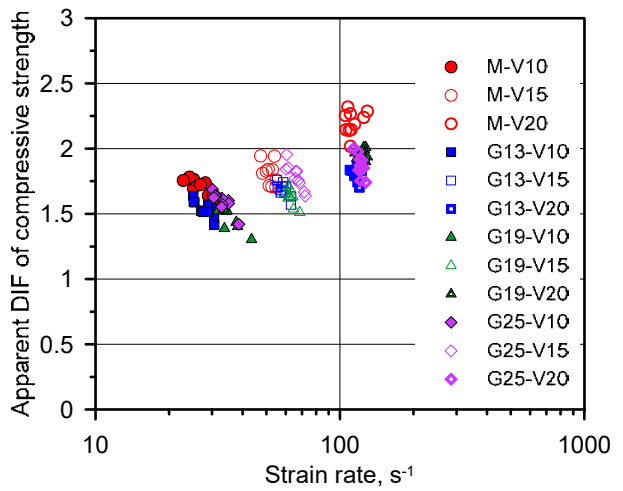

(a)

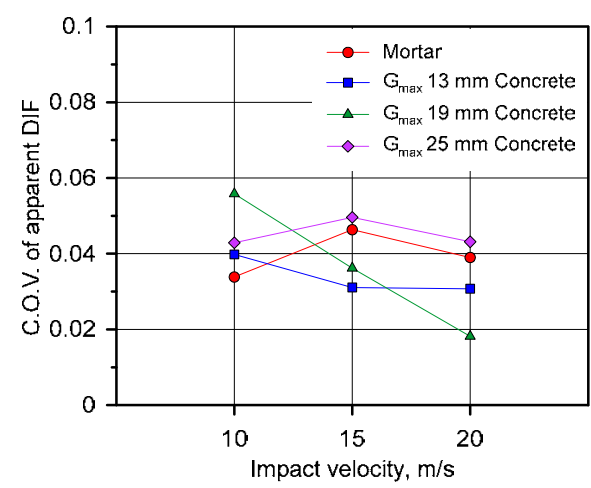

(b)

Figure 2: (a) Apparent DIF of test results; (b) C.O.V. of apparent DIF of test results. 
from nonlinear regression analysis for each group of maximum aggregate size according to Lee et al. [1]. Each value is listed in Table 4.

As shown in Fig. 3, mortar specimen shows the highest pure rate DIF

$$
D I F_{\text {rate }}=\left(\frac{\dot{\varepsilon}_{S}}{\dot{\varepsilon}_{s, \text { static }}}\right)^{k_{1}} \text {. }
$$

\section{CONCLUSION}

In this study, to figure out the effect of maximum aggregate size on SHPB test of concretelike material, the experiment was conducted with 120 specimens under the same test conditions except for the maximum aggregate size.

The test results show that the effect of maximum aggregate size is not related to the heterogeneity of the specimens. However, by comparing the pure rate DIF, difference of the strength enhancement was confirmed. Therefore, it is suggested that the test results of the specimens with small aggregate or mortar cannot be shown as representing the genuine dynamic material behaviour.

As a result, to obtain precise dynamic material properties, especially for the dynamic compressive strength, the same maximum aggregate size with the aggregate used in practice should be used.

Table 4: $k_{1}$ value obtained from SHPB test data by using nonlinear regression analysis [1].

\begin{tabular}{|c|c|}
\hline & $k_{1}$ \\
\hline Mortar & 0.0393 \\
\hline $\mathrm{G}_{\max } 13 \mathrm{~mm}$ concrete & 0.0322 \\
\hline $\mathrm{G}_{\max } 19 \mathrm{~mm}$ concrete & 0.0249 \\
\hline $\mathrm{G}_{\max } 25 \mathrm{~mm}$ concrete & 0.0340 \\
\hline
\end{tabular}

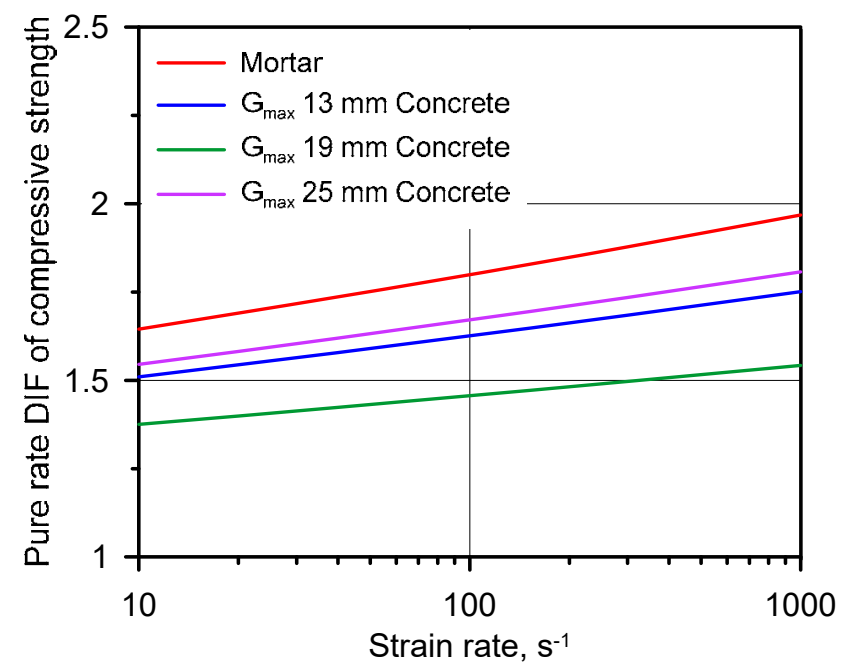

Figure 3: Pure rate DIF obtained from SHPB test data. 


\section{ACKNOWLEDGEMENTS}

This work was supported by the Infrastructure and Transportation Technology Advancement Research Program funded by the Ministry of Land, Infrastructure and Transport of Korean government [grant number 17CTAP-C129906-01]; the National Research Foundation of Korea (NRF) grant funded by the Korea government [grant number NRF2017R1A2B2003640].

\section{REFERENCES}

[1] Lee, S., Kim, K.-M., Park, J. \& Cho, J.-Y., Pure rate effect on the concrete compressive strength in the split Hopkinson pressure bar test. International Journal of Impact Engineering, 113, pp. 191-202, 2018.

[2] Hao, H., Hao, Y. \& Li, Z.-X., A numerical study of factors influencing high-speed impact tests of concrete material properties. Proceedings of the 8th International Conference on Shock and Impact Loads on Structures, CI-Premier Pte Ltd: Adelaide, 2009.

[3] Hao, Y. \& Hao, H., Numerical evaluation of the influence of aggregates on concrete compressive strength at high strain rate. International Journal of Protective Structures, 2(2), pp. 177-206, 2011.

[4] Hao, H., Hao, Y. \& Li, Z.-X., Numerical analysis of lateral inertial confinement effects on impact test of concrete compressive material properties. International Journal of Protective Structures, 1(1), pp. 145-167, 2010.

[5] Chen, X., Wu, S. \& Zhou, J., Experimental and modeling study of dynamic mechanical properties of cement paste, mortar and concrete. Construction and Building Materials, 47, pp. 419-430, 2013.

[6] Hao, Y., Hao, H., Jiang, G.P. \& Zhou, Y., Experimental confirmation of some factors influencing dynamic concrete compressive strengths in high-speed impact tests. Cement and Concrete Research, 52, pp. 63-70, 2013. 